\& J. Edu. \& Sci., Vol. (24), No. (1) 2011 \&

\title{
Determination of Glucose Concentration By Rotation of Polarization Plane of He-Ne Laser
}

\author{
Zead T. Ahmed Ameer F. Hammeed \\ Department of Physics / College of Education \\ University of Mosul
}

Received

08/ $06 / 2009$
Accepted

$10 / 12$ / 2009

\section{الخلاصة}

تم في هذا البحث دراسة الفاعلية الضوئية لمحلول سكر الكلوكوز من خلال دراسة تأثثر هذا المحلول في دوران مستوى الاستقطاب لشعاع ليزر He-Ne، إذ نم اختيار تراكيز مختلفة

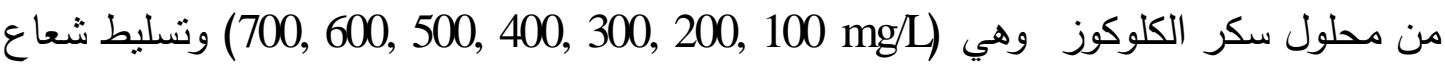
الليزر المستقطب على كل نموذج من التزاكيز المحضرة وتحليل الثنعاع النافذ من المحلول

بوساطة محلل وذلك بتغيير الناوية بين مستوى نفاذ المحلل ومسنوى استقطاب شعاع الليزر

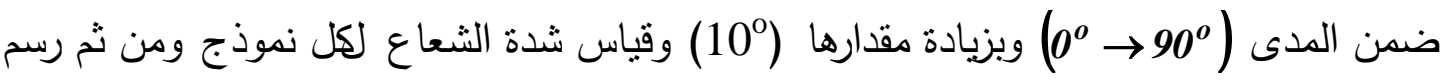
العلاقة بين قيم زاوية المحلل مع الثدة النافذة من المحلل للماء المقطر ولكل تركيز من محلول السكر ، ومن خلال مجموعة المنحنيات هذه نم تحديد زاوية المحلل عند قيمة واحدة للثدة للماء للهاء المقطر ولكل تركيز والتي عندها يحدث تغير في سلوك المنحنيات ، ومن رسم العلاقة بين قيم الزوايا المحددة مع قيم التراكيز نم استتناج العلاقة بين تركيز المحلول وزاوية الدوران ووجد أنها علاقة خطية. من جهة أخرى نم دراسة توزيع الثدة في بقعة ليزر He-Ne بالأبعاد الثلاثة والنافذة من

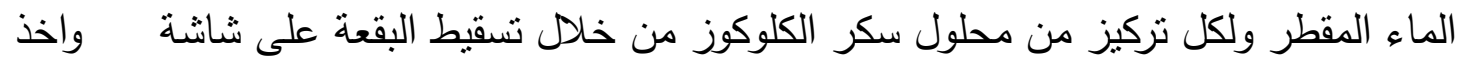
صورة للبقعة باستخدام كاميرا رقمية ومن معالجة الصور باستخدام MATLAB Package

\section{Abstract}

In this research, the optical activity of glucose solution had been studied through the studying of influence of this solution in rotation of polarization plane of laser $\mathrm{He}-\mathrm{Ne}$ light, the different concentrations of 
glucose solution were selected for analyzing the intensity of polarized laser light within the range $\left(\boldsymbol{0}^{\boldsymbol{o}} \rightarrow \mathbf{9 0}^{\circ}\right)$ and by increment $\left(10^{\circ}\right)$, which is transmitted during the samples of distilled water (as a standard sample) and these different concentrations of glucose solution by using analyzer. Then the relationship between values of analyzer angles and intensity values was plotted. At steady intensity for all curves the analyzer angle for distilled water and each one of concentrations has determined, then all concentrations were plotted as a function of these angles and by fitting the result curve by using MATLAB Package the polynomial of first order which represents the relationship between the rotational angle and concentrations had inquired.

In other hand, the distribution in (3-D) of intensity of He-Ne laser spot which is transmitted during the samples of distilled water and the different concentrations of glucose solution was studied through taking the image for each case by using digital camera. The difference in distribution of intensity in spot of laser for each case had determined that due to different in solution concentrations.

\section{1- Introduction}

When a beam of plane-polarized light is directed along the optic axis of quartz, it is found that the plane of polarization turns steadily about the direction of the beam, as shown as in Fig (1), and emerges vibrating in some other plane than that at which it entered. The amount of this rotation is found experimentally to depend upon the distance traveled in the medium and upon the wavelength of the light. The former fact shows that the action occurs within the medium and not at the surface. This phenomenon of the rotation of the plane of vibration is frequently called optical activity, and many substance are now known to exhibit the effect. Some of these are cinnabar, sodium chlorate, turpentine, sugar crystals, sugar in solution, and sulfate of strychnine.[3]

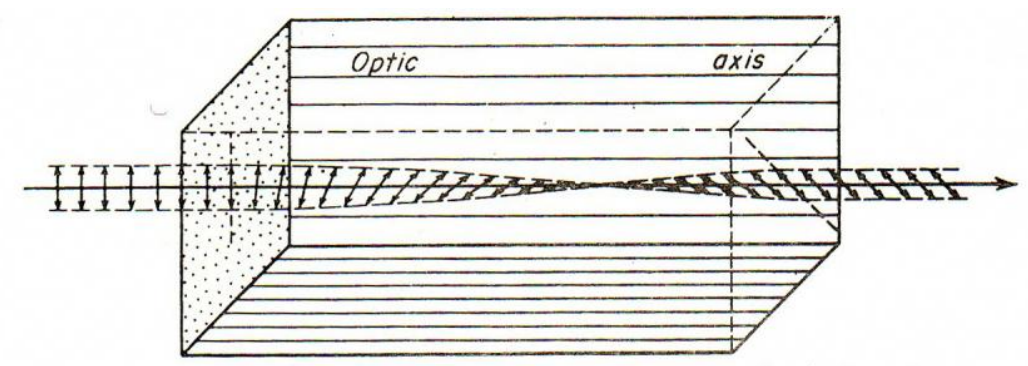

Fig (1): Rotation of the plane of vibration in an optically active substance

Some quartz crystals and sugar solution rotate the plane of vibration to the right and some to the left. Substance which rotate to the 
right are called dextrorotatory or right-handed, and those which rotate to the left are called levorotatory or left-handed. By "right-handed rotation" is meant that upon looking against the oncoming light the plane of the vibration is rotated in a clockwise direction. Left-handed substance rotate the light counterclockwise.[3]

In the recent studies, the using of polarized light is more benefit from that unpolarized light for investigation the properties of materials. One researches in this field, the optical sensor based on kertschman SPR technique was used to detect the sugar content in commercial carbonated drinks by using polarized laser and the results show that the shift of resonance angle $\left(\Delta \theta_{\text {spr }}\right)$ increases linearly with the sugar content. [5]

Anther research the red and yellow laser monochromatic radiations have been used, radiation from the middle of PAR range (Photosynthetic Active Radiation) and the influence of the polyethylene film on the polarization properties of the light is studied where the polyethylene used for plants as a glazing material.[2]

\section{2- Theory}

\section{2-1 Optical Rotation}

Certain compounds, mostly organic (notably those containing asymmetric carbon atoms) rotate the plane of polarized light. The phenomenon is called optical rotation and such substances optically active compounds. Measuring angle of rotation the concentration of a substance in a solution is determined.[1]

The measured angle of rotation depends upon many variables:

- The type or nature of sample (example: sugar solution).

- Concentration of the optical active components.

- The length of the sample tube.

- The wavelength of the light source.

- Temperature.

\section{2-2 Rotation in Liquid}

The rotation of the plane of vibration by liquid was discovered quite accidentally by Biot in 1811. He found that turpentine behaved like quartz in producing a rotation proportional to the light path through the substance and very nearly proportional to the inverse square of the wavelength. In such cases the rotation is attributable to the molecule structure itself. In fact, most liquid exhibiting rotation are organic compounds involving complex molecules.[3]

Each molecule of a liquid may be thought of as a small crystal with an optic axis along which plane-polarized light is rotated. Since in a liquid the molecules are oriented at random, the observed rotation is an average effect of all the molecules and therefore the same in any direction 
through the liquid. One might at first sight think that the random orientation of the molecules would cancel out the rotatory effect entirely. But the molecules has a screw like arrangement of atoms, and a righthanded screw is always right-handed, no matter from which end it is viewed.[3]

Liquid made up of an optically active substance and an inactive solvent are found to produce a rotation very nearly proportional to the amount of the active substance present. This has led to the very wide use of polarized light in industry as an accurate means of determining the amount of sugar, an optically active substance, in the presence of nonactive impurities. The specific rotation or rotatory power is defined as the rotation produced by a $10-\mathrm{cm}$ column of liquid containing $1 \mathrm{gm}$ active substance for every cubic centimeter of solution. This may be written as an equation:[1,3]

$[\rho]_{\lambda, P H}^{T}=\frac{10 \theta}{l d}$

where $[\rho]$ is the specific rotation, $d$ the number of grams of active substance per cubic centimeter, $l$ the length of the light path in centimeters, and $\boldsymbol{\theta}$ the angle of rotation.

In general, the rotation in liquids is considerably less than in crystals. For example, $10 \mathrm{~cm}$ of turpentine rotates sodium light $-37^{\circ}$ (the minus sign indicates left-handed or counterclockwise rotation, looking against the direction of propagation). An equal thickness of quartz, on the other hand, rotates sodium light $2172^{\circ}$. It is for this reason that the specific rotation for crystals is taken as the angle for a 1-mm path.[3]

Careful determinations of the rotatory power of an optically active substance in various non-active solvent have given slightly different result. There is a variation not only with solvents but with the concentration of the active substance. From experiment the rotatory power is found to be adequately given by:[3]

$\rho=L+M d+N d^{2}$

where $\boldsymbol{L}, \boldsymbol{M}$ and $\boldsymbol{N}$ are constant and $\boldsymbol{d}$ is amount of the active material in solution.

In practical measurements readings are taken at different units: $\rho$ in $\left({ }^{\mathrm{o}} \mathrm{deg}\right), \boldsymbol{d}$ in $\mathrm{g} / \mathrm{cm}^{3}, l$ in $\mathrm{dm}$ and so $[\rho]_{589 n m}^{20}$ is usually tabulated in ${ }^{0} \mathrm{~cm}^{3} / \mathrm{g} \mathrm{dm}$. As shown in table (1).

Table (1): Specific rotation for some type of sugar by using light with wave length $(589 \mathrm{~nm})$ at temperature $\left(20^{\circ} \mathrm{C}\right)[1]$

\begin{tabular}{|c|c|}
\hline $\begin{array}{c}\text { Substance in a solution } \\
\mathrm{H}_{2} \mathrm{O} \text { solvent }\end{array}$ & $\begin{array}{c}\text { Specific rotation } \\
{\left[\boldsymbol{\rho}_{\mathbf{5 8 9}}^{\mathbf{2 0} \text { m }}\right.} \\
\left(\mathrm{deg} \mathbf{c m}^{3} / \mathrm{g} . \mathrm{dm}\right)\end{array}$ \\
\hline Sucrose & +66.54 \\
\hline Glucose & +52.74 \\
\hline Fructose & -93.78 \\
\hline Maltose & +137.5 \\
\hline Lactose & +55.3 \\
\hline Dextrose & +194.8 \\
\hline
\end{tabular}




\section{3- Experimental part:}

Fig(2) shows the experimental setup for studying the influence of the concentration of glucose solution on polarization plane of He-Ne laser, different concentrations have been used for this purpose which are $(100,200,300,400,500,600,700) \mathrm{mg} / \mathrm{L}$.

It is clear that, the setup contains unpolarized $\mathrm{He}-\mathrm{Ne}$ laser $\left(6328 \mathrm{~A}^{\mathrm{o}}\right)$, polarizer, tube of solution, analyzer and photo-diode detector which were aligned in one optical axis. When the laser switch on the polarized laser beam has applied towards sample tube which containing the glucose solution and by changing the analyzer angle $\left(\theta=\boldsymbol{0}^{\circ} \rightarrow \mathbf{9 0}^{\circ}\right)$ by step $\left(10^{\circ}\right)$, the output intensity from analyzed was measured, this procedure has been repeated for each above concentrations, Also the measurements above were carried out on distilled water as a standard sample.

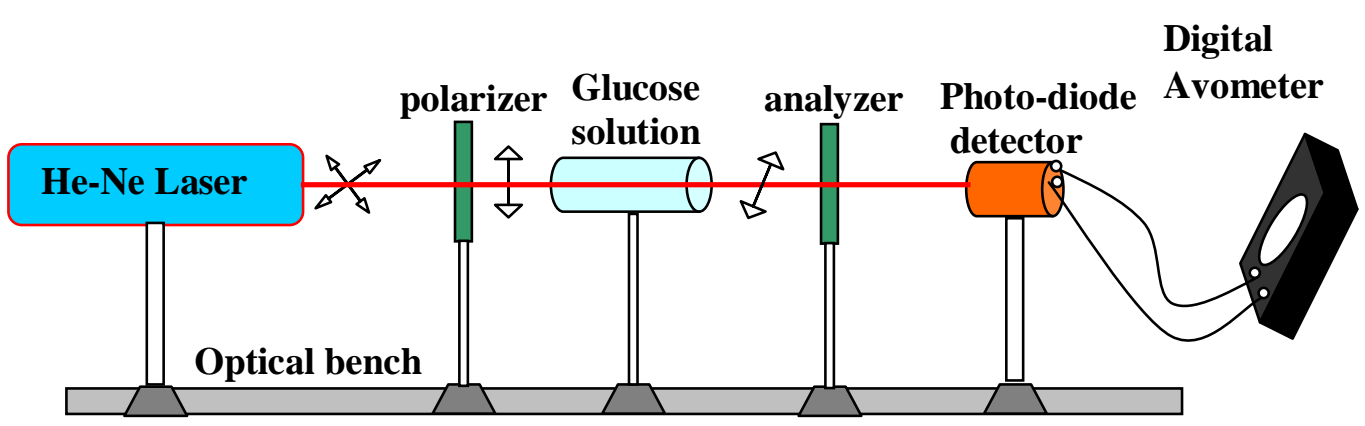

Fig(2): Experimental setup used for Studying the rotation of polarization plane by glucose

Finally, the influence of glucose solution on the He-Ne laser light distribution was studied thoroughly the placing the solution sample in a way of polarized laser and observing the output spot of laser on a screen and by using digital camera the spot image was taken. The images were then fed to the computer for analysis and image processing.

\section{4- Results and Discussion}

Fig (3) shows the ordinary variation of light intensity as a function of analyzer angle with different values of glucose concentration. As a matter of fact this variation is known as Malus law, the figure illustrate also the effect of the concentration. This figure is an essential property of any polarization to be used in any inspection.

Glucose concentration has been influence the rotational angle, as shown in Fig(4). This figure shows the increment of the rotational angle with increasing of Glucose concentration $(\mathrm{mg} / \mathrm{L})$ as a nonlinear relation which was accepted with the equation (2) (second order equation) and for the best fit obtained from the MATLAB package the values of the equation factors are: 
$\rho=L+M d+N d^{2}$

$$
L=0.0099 \quad M=-0.0011 \quad N=3.385 \times 10^{-6}
$$

Because of the value of the term $\left(\boldsymbol{N} \boldsymbol{d}^{2}\right)$ is very small we can ignore it, then the second order equation above approach to be linear equation such as equation (1), the value of the slope of line is (0.00000124) deg.L/mg that mean the value of specific rotation $[\rho]_{632.8 n m}^{T}$ for glucose solution by using equation (1) is $\left(29.4664^{\circ}\right)$.

This nonlinearity in the graph could be explained that the optical activity of any sugar solution exhibit activity as given by equation (2). Approach for the influence of the glucose concentration on the $\mathrm{He}-\mathrm{Ne}$ laser light distribution (3-D) will be shown for different values of glucose concentration. This approach can be implemented for in vivo of diabetes. Figs (5), (6), (7) and (8) show the (3-D) laser distribution for distilled water and three different selected concentrations of glucose using MAT. Package, these images can be directly gives us the glucose concentration by observing the increasing in the bandwidth of Gaussian distribution with increasing the concentration of glucose solution. In the other hand, the optical activity of glucose solution can be explained by the reduction of the peak of the intensity of the laser spot, It is clear that in Fig(5) which represent the distilled water the value of intensity of laser spot was maximum but it reduces by increasing the concentration of glucose solution as in Figs (6), (7) and (8), that means the polarized plane of the output laser spot has been rotated gradually with increasing glucose concentration.

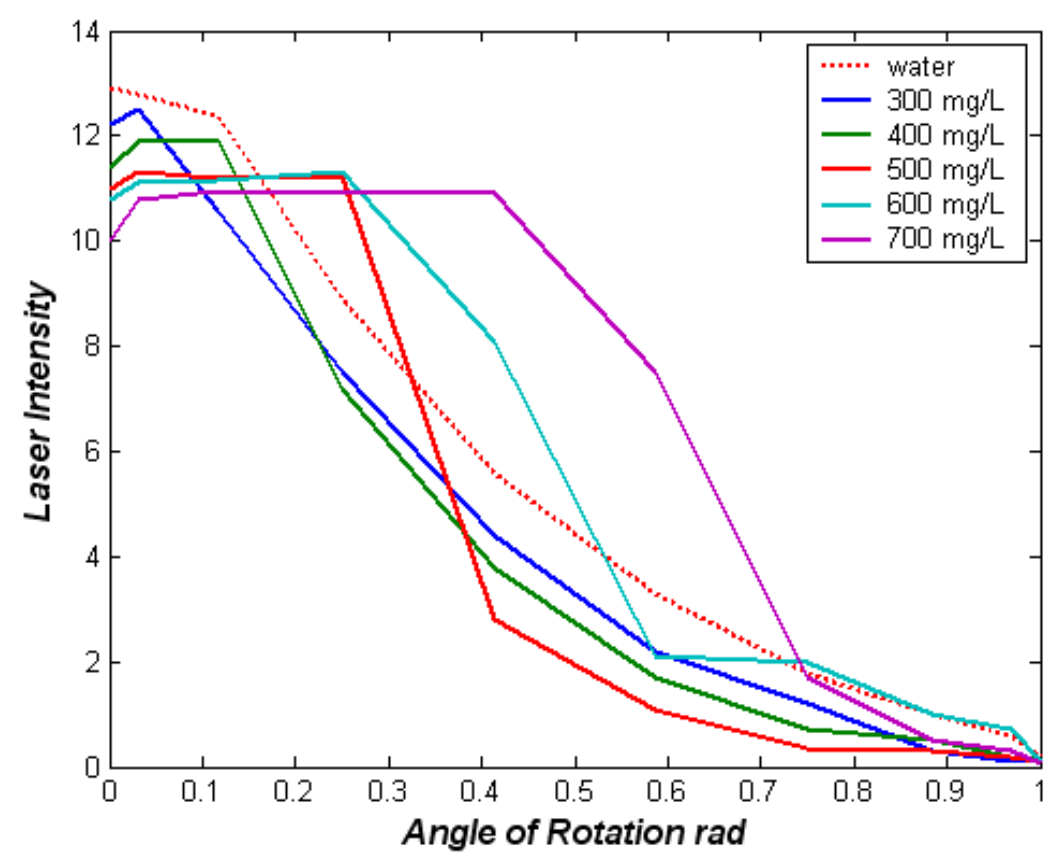

Fig(3): Laser intensity output from analyzer as a function of analyzer angle. 


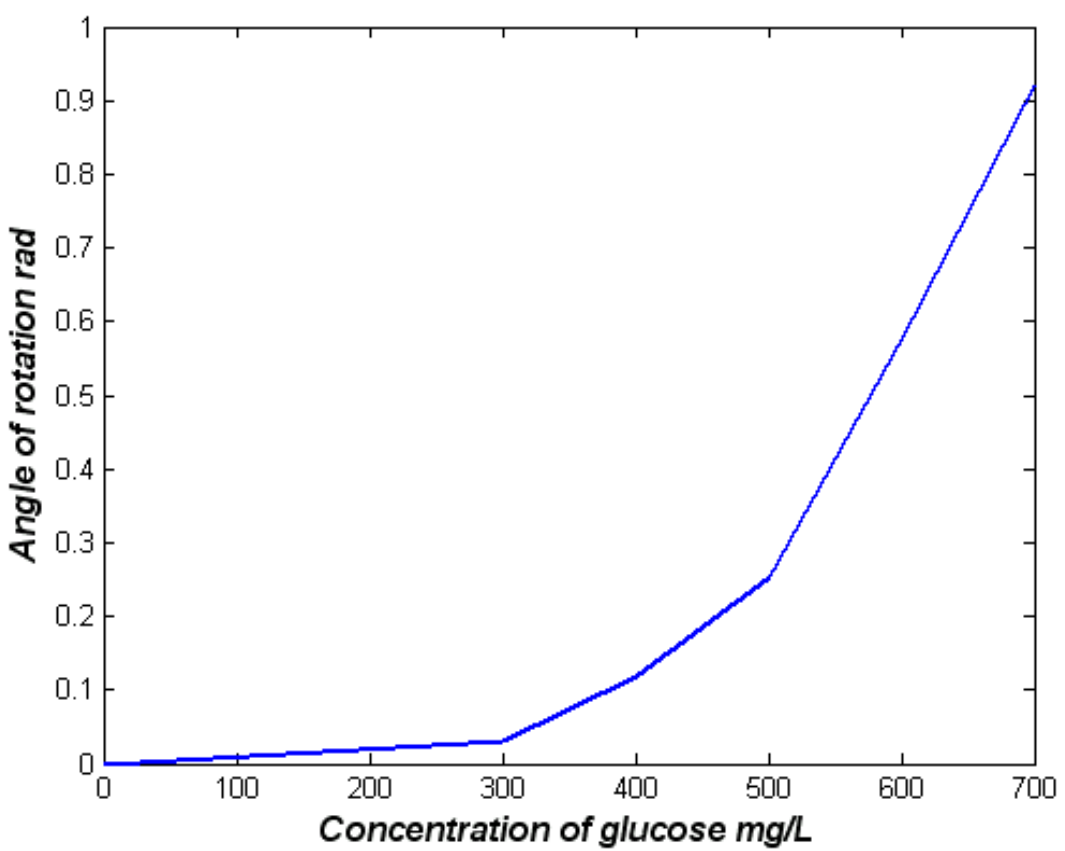

Fig(4): Variation of rotational angle of polarized laser as a function of glucose concentration.

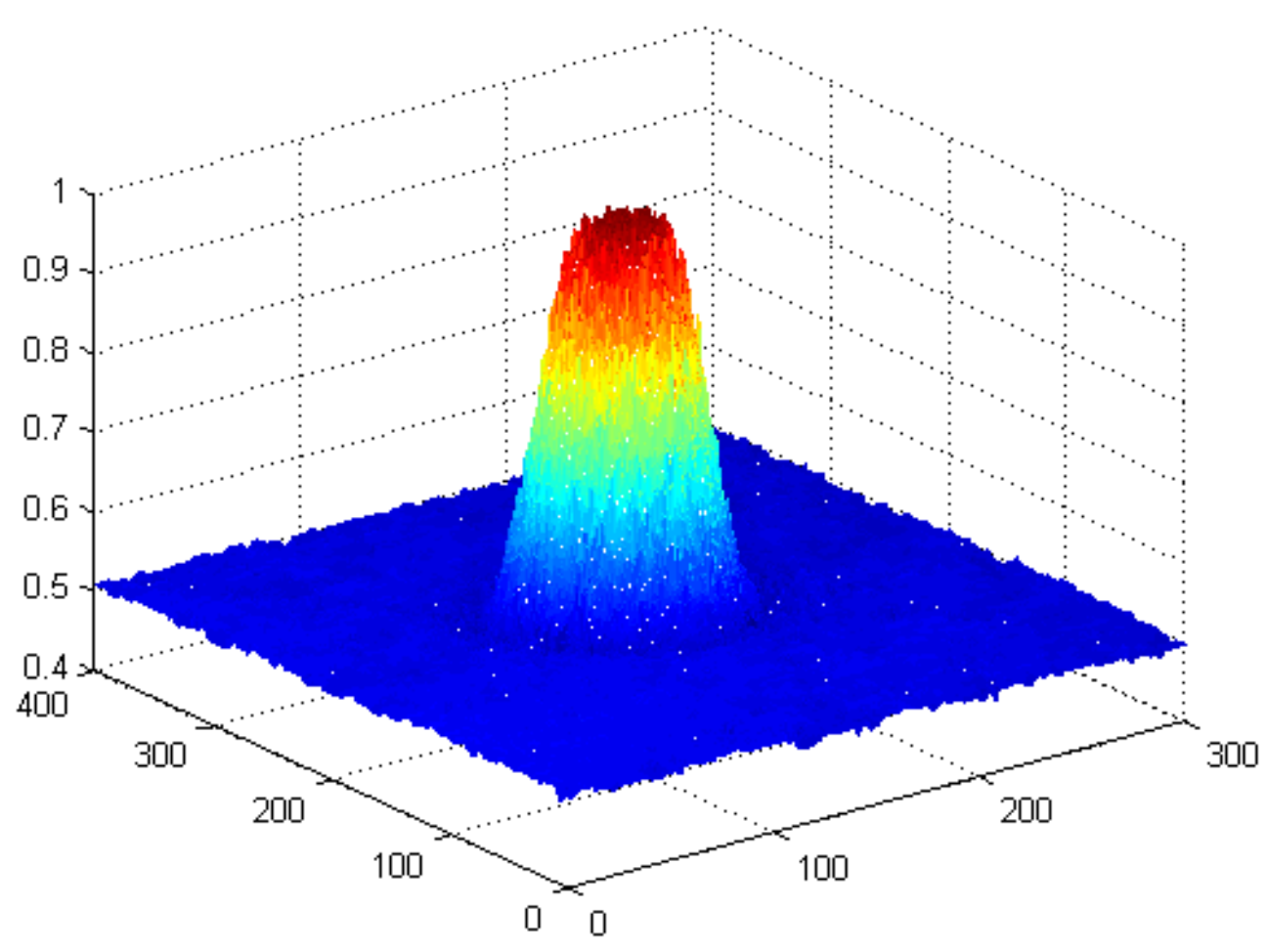

Fig(5): Intensity distribution (3-D) of output laser spot for distilled water. 


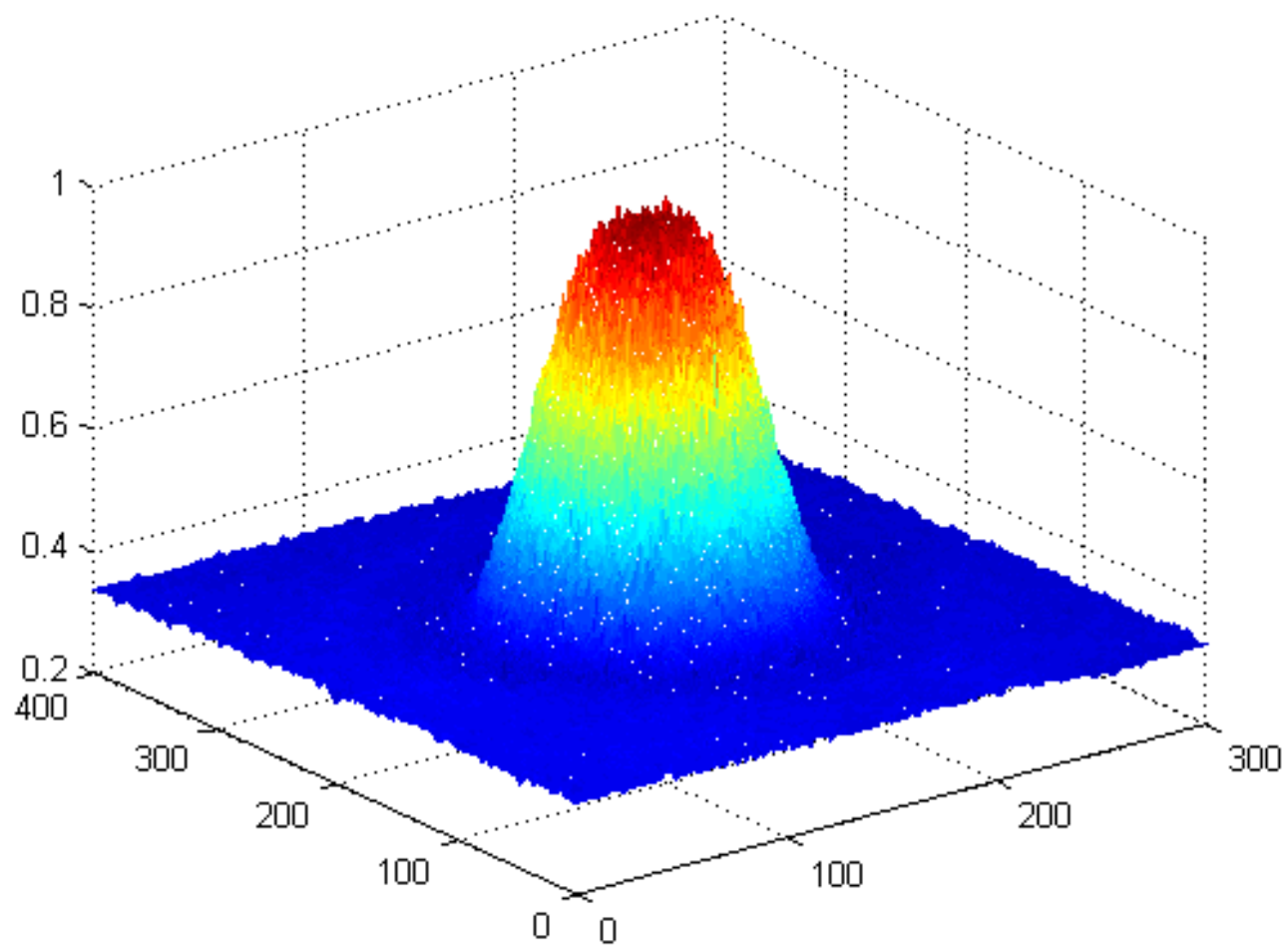

Fig(6): Intensity distribution (3-D) of output laser spot for glucose solution with concentration $(300 \mathrm{mg} / \mathrm{L})$.

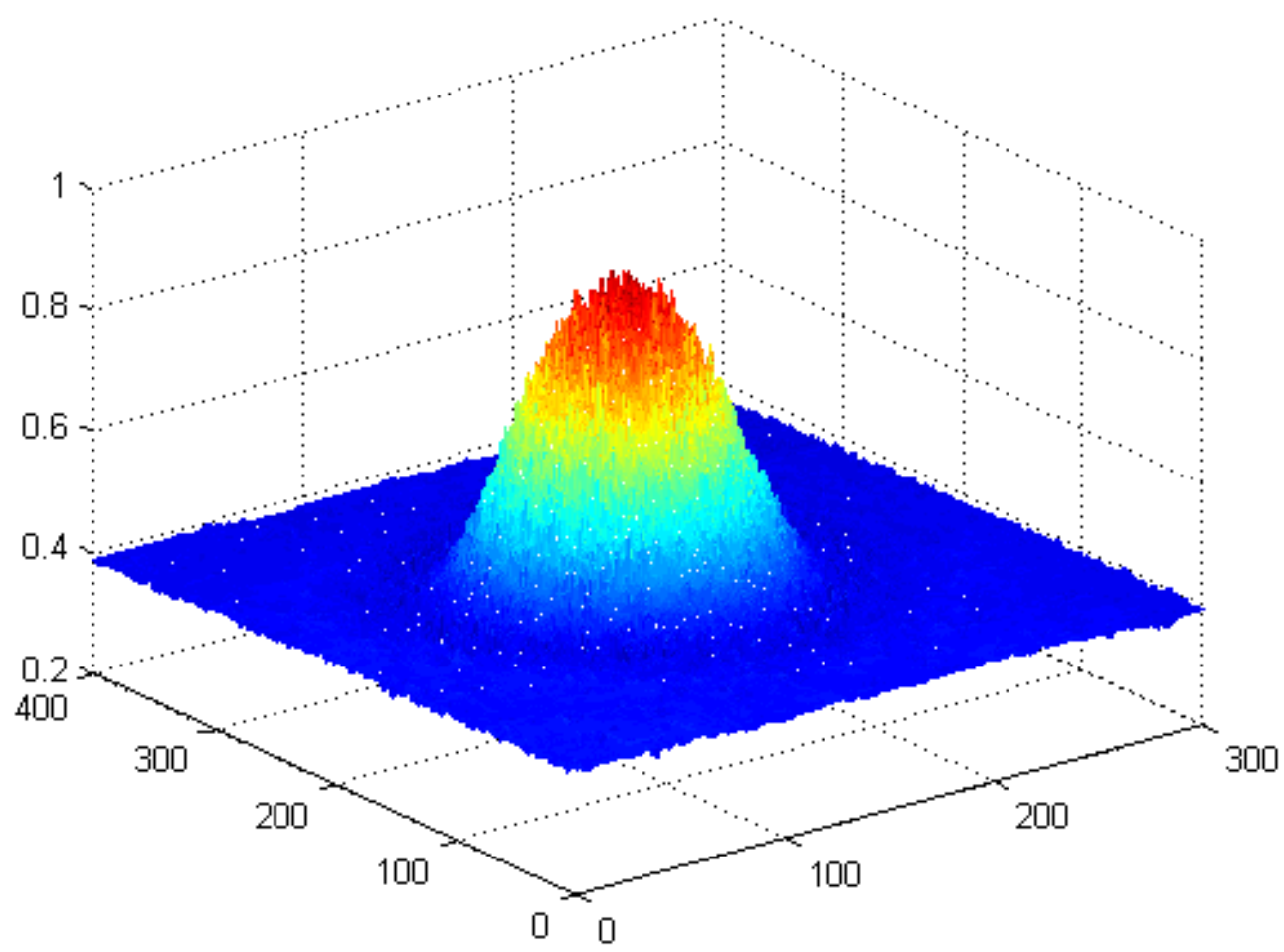

Fig(7): Intensity distribution (3-D) of output laser spot for glucose solution with concentration $(500 \mathrm{mg} / \mathrm{L})$. 


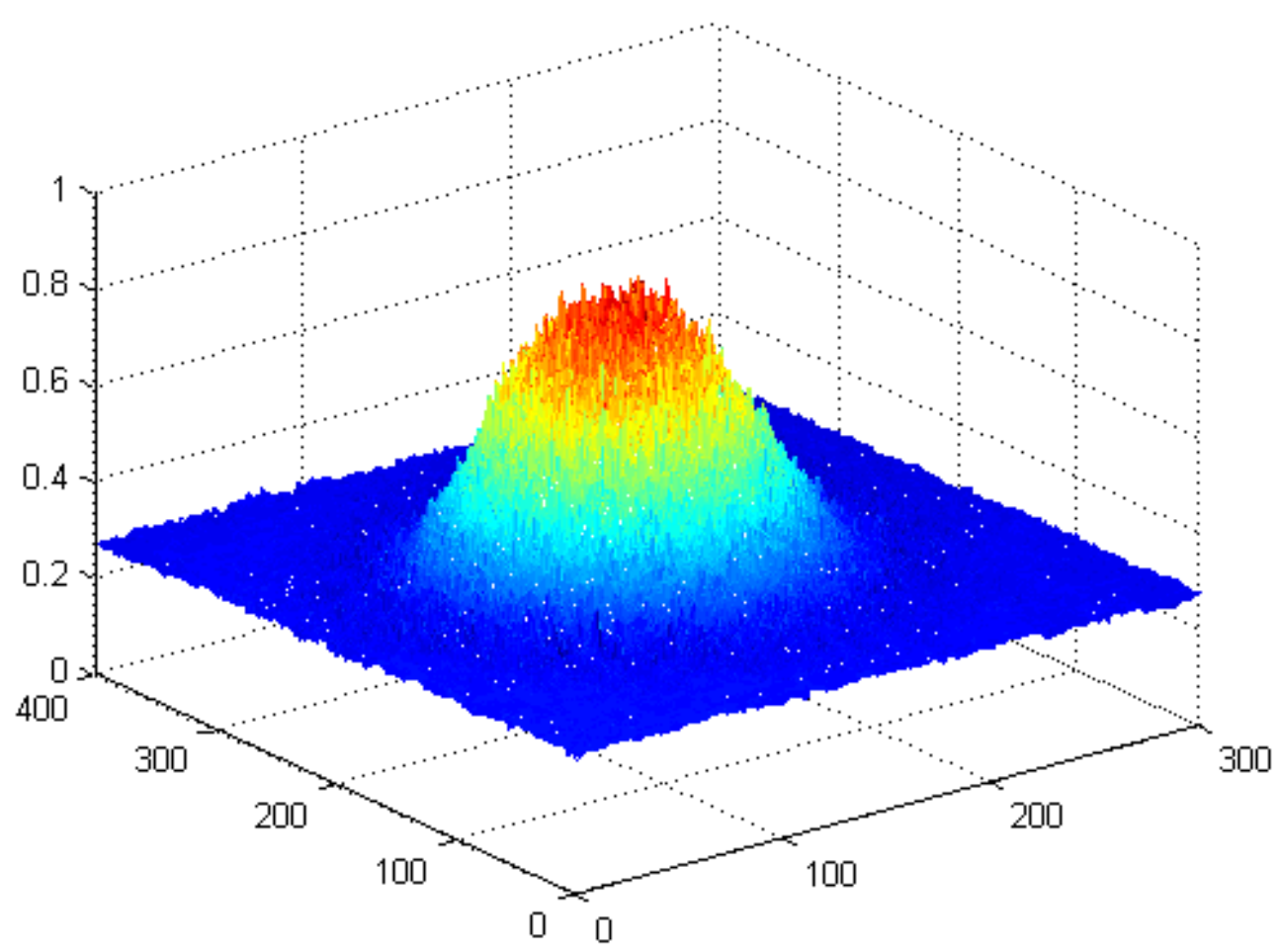

Fig(8): Intensity distribution (3-D) of output laser spot for glucose solution with concentration $(700 \mathrm{mg} / \mathrm{L})$.

\section{Conclusions}

The studied of glucose solution has a significant influence on the polarized He-Ne laser which is explained that glucose solution in a specific concentration rotates the polarization plane of He-Ne laser in a specific angle, this benefit in vivo test for diabetes to determinate the sugar content in blood. The processing image of the output laser spot shows that the peak of intensity reduces with increasing glucose concentration because of the rotation of polarization plane of laser.

\section{References}

1) Bozic, J.S., Ogrin,T., "Polarimetry", Josef Stefan Institute.

2) Dontu, S., Brezeanu, T., Ristici, E., Cotiplan, C., "Polarization Changes on Transmitted Laser Light By a Polyethylene Film", Romanian J. Biophys., Vol.16, No.1,P.63-67,Bucharest,2006

3) Jenkins, F.A., White,H.E., "Fundamentals of optics", $3{ }^{\text {rd }}$ edition, McGraw-Hill,Book Comp.Inc, 1957.

4) Ruau, L., Jewell, S.A., Sambles, J.R., "Polarization Rotate Using a hybrid Aligned Nematic Liquid Crystal Cell", Optical Society of America,Vol.15, No.7,Optical Express 4192, 2007.

5) Yusmawati, W.Y.W., Chuah, H.P., Mahmood, M.Y.W., "Optical properties and Sugar Content Determination of Commercial Carbonated Drinks using Surface Plasmon Resonance", American journal of Applied Sciences 4(1):01-04,2007, ISSN1546-9239. 